\title{
Grain sorting in the morphological active layer of a braided river physical model
}

\author{
P. Leduc, P. Ashmore, and J. T. Gardner \\ University of Western Ontario, Department of Geography, London, Ontario, Canada \\ Correspondence to: P. Leduc (pleduc3@uwo.ca)
}

Received: 8 June 2015 - Published in Earth Surf. Dynam. Discuss.: 10 July 2015

Revised: 22 October 2015 - Accepted: 23 November 2015 - Published: 15 December 2015

\begin{abstract}
A physical scale model of a gravel-bed braided river was used to measure vertical grain size sorting in the morphological active layer aggregated over the width of the river. This vertical sorting is important for analyzing braided river sedimentology, for numerical modeling of braided river morphodynamics, and for measuring and predicting bedload transport rate. We define the morphological active layer as the bed material between the maximum and minimum bed elevations at a point over extended time periods sufficient for braiding processes to rework the river bed. The vertical extent of the active layer was measured using 40 hourly high-resolution DEMs (digital elevation models) of the model river bed. An image texture algorithm was used to map bed material grain size of each DEM. Analysis of the 40 DEMs and texture maps provides data on the geometry of the morphological active layer and variation in grain size in three dimensions. By normalizing active layer thickness and dividing into 10 sublayers, we show that all grain sizes occur with almost equal frequency in all sublayers. Occurrence of patches and strings of coarser (or finer) material relates to preservation of particular morpho-textural features within the active layer. For numerical modeling and bedload prediction, a morphological active layer that is fully mixed with respect to grain size is a reliable approximation.
\end{abstract}

\section{Introduction}

Information about the distribution of grain sizes within a volume of an alluvial gravel river bed is sought for a variety of reasons. The focus here is the relationship between grain size sorting in the river bed and bed material transport rates, which is central to explaining, modeling and predicting the morphological development of a river. The goal of the analysis described in this paper is to characterize the grain size sorting of the morphological active layer aggregated over an area of the full width of a gravel-bed braided river in a nonaggrading or degrading state.

Gravel braided rivers have intricate patterns of size sorting driven by complex flow structures at confluences and in shallow (typically the mean depth/ $D_{90}$ in anabranches is 10 or less) flows associated with bifurcations and sorting in low sinuosity bends and point bars as well as in migrating bedload sheets and low-amplitude bars (Bluck, 1979; Ashworth et al., 1992). The amplitude of topography, and therefore the turnover depth for gravel, related to these local erosional and depositional features is commonly up to 20 times $D_{50}$ (Gardner and Ashmore, 2011; Wheaton et al., 2013). The surface and near-surface sorting of grain sizes associated with the active morphological processes of braided rivers results in patterns of grain size related to local bed elevation and flow structure. These patterns are preserved within the river deposits as the anabranches migrate and rework previously deposited material. Surface patchiness has been observed in flume experiments in response to input sediment flux variations or topography control. The importance of this patchiness has previously been considered mainly in relation to the bed surface characteristics and the effect on local roughness and bed material load (Nelson et al., 2009, 2010).

We introduce the term "morphological active layer" to refer to the sediment involved in the mixing, sorting and exchange over the full amplitude of the developing bed topography over extended time periods. The core question addressed here is whether the morphological active layer is homogeneous with respect to trends in grain size between lay- 
ers and aggregated at the scale of the braided channel. The answer to this question is important for understanding the morphodynamic and sedimentary processes of braided rivers and the methods for representing these processes in computational models (Viparelli et al., 2010; Sun et al., 2015). Understanding the sedimentology of the morphological active layer is also important for calculation of bedload transport rates using morphological methods from direct river survey (Wheaton et al., 2013) that integrate transport rates over morphologically significant events and extent (Ashmore and Church, 1998). Refining morphological transport estimates may require information on grain sizes encountered at different depths below the bed or confirmation (or modification) of the simple assumption that, during channel-forming processes, all grain sizes of the bulk grain size distribution are available with equal probability.

Data on three-dimensional patterns of sorting within the bed are difficult to acquire, especially for an entire volume of the bed in a river reach. In sedimentological analyses, descriptions of braided river gravels have tended to emphasize the sedimentary structure and sedimentological detail with little direct analysis of grain size sorting except for limited vertical sections, trenches or cores using direct physical grain measurement or indirect grain size methods such as imagebased automatic sizing (Storz-Peretz and Laronne, 2013a). Analyses have typically focused on facies patterns and sedimentary structure, but several have mentioned that there is little vertical trend in grain sizes in braided river gravels (e.g., Bluck, 1979; Sambrook Smith, 2000; Heinz et al., 2003; Lunt and Bridge, 2004; Guerit et al., 2014; Marren, 2005; StorzPeretz and Laronne, 2013b). Similarly, physical models of aggraded braided gravel alluvium show patches and threads of distinct facies but no clear trend in grain size (e.g., Moreton et al., 2002). However, these generalities, while useful indications, are based on limited sampling and quantification of trends in particle size sorting.

Analyses of the statistics of vertical tracer particle exchange for different size fractions have been used in developing observations and theories of particle kinetics for bedload prediction based on long-term mixing and burial/exhumation within the particle exchange layer (Haschenburger, 2011). This relates partly to the development of bed surface armor and the size of material available for transport at different phases of particle mobility. These analyses are usually restricted to the bedload exchange layer, which is generally taken to extend to about $2 \times D_{90}$ beneath the river bed (although deeper exchange is possible; Haschenburger, 2011) and is also observationally restricted by the methods for locating tracer particles beneath the bed. These analyses provide information for particle exchange and bedload theory for vertically stable beds with limited topographic amplitude. In braided rivers, bed topography can change rapidly during normal channel-forming events due to local bed scour, deposition and channel avulsion so that exchange depths are likely to extend through the entire range of bed elevation (of the order of $10 \times D_{90}$ ) rather than the relatively thin grain exchange layer of more stable river beds. This is a primary reason to define a morphological active layer that is distinct from the grain exchange active layer related to flood events on a stable gravel bed with limited topographic amplitude.

The grain size characteristics of the morphological active layer are needed for implementing numerical models of braided river morphodynamics. Prior studies of gravel bed stratigraphy under aggradation/degradation have used plane beds in narrow flumes, rather than fully developed river models (Viparelli et al., 2010). In the plane bed case, with no lateral or other morphological sorting, the surface layers of the bed tend to be coarser than the lower layers (Viparelli et al., 2010). The variety of sorting mechanisms at work in laterally unstable rivers with substantial depths of scour and deposition associated with, for example, confluences and braid bars may modify this trend (Leduc, 2013). New numerical model results have begun to yield predictions of local grain size sorting in braided channels (Sun et al., 2015), and physical experiments in small-scale models will be valuable in developing and testing these numerical models.

We expect complex three-dimensional arrangements of patches of varying grain composition in the morphological active layer that are locally heterogeneous (Gardner and Ashmore, 2011), but the core objective here is to establish whether there is any systematic aggregate vertical trend in the average grain sizes in a river reach. Braided river deposits and exposures in the field might provide some of this information, but the sample requirements are Herculean and would not, strictly, include the whole morphological active layer because our definition of this layer (see above) makes it distinct from the lithosome (Bluck, 1979) that is of direct interest for sedimentology. Formation of the morphological active layer requires a long period of active braiding and reworking of the entire braided channel. Our solution is to use a small-scale physical model of a gravel-bed braided river from which digital elevation maps and grain size maps can be extracted over an extended time period. The sequence of DEMs (digital elevation models) and grain size maps was compiled to produce the morphological active layer characteristics, using the idea and method developed by Gardner and Ashmore (2011) based on photogrammetry image texture analysis. Van De Lageweg et al. (2013) used this approach to characterize deposit geometry in a small-scale flume model of a braided river (with topography acquired with a laser scanner), but their models do not physically scale grain size distributions for gravel bed rivers and so do not yield textural information. Laser scanning and other technologies may yield equivalent data in the field but would still potentially require years of data acquisition, and periodically dry river bed, to reproduce what is possible in tens of hours in a physical model. 


\section{Flume procedure and data collection}

The experiment described here previously formed the basis for an analysis of the topography, grain size and formation of the basal surface of braided river deposits (Gardner and Ashmore, 2011). Here we expand the analysis to focus on grain size characteristics within the entire vertical extent of DEM data and based on refinement of the topographic and textural data, extraction of complete grain size maps, and extension of the time period analyzed from 20 to $40 \mathrm{~h}$ of model running time.

\subsection{Flume procedure}

The data are taken from a single experiment using a Froudescale physical model of a gravel-bed braided river in a flume $18 \mathrm{~m}$ long, $3 \mathrm{~m}$ wide and $0.3 \mathrm{~m}$ deep. The grain size distribution was scaled at $1 / 30$ from measurements of the gravel (truncated at $8 \mathrm{~mm}$ in the field) particle size distribution of a pro-glacial braided reach of Sunwapta River in the Canadian Rocky Mountains. Consequently, bed material in the model was composed of sand with sieve sizes ranging from 0.3 to $8 \mathrm{~mm}$ and a median size of about $1.3 \mathrm{~mm}$. The geometric sorting defined by $\sigma=\frac{d_{84}-d_{16}}{4}+\frac{d_{95}-d_{5}}{6.6}$ is equal to 1.3 , with $d_{X}$ being the $x$ th percentile of the distribution. This grain size distribution was designed to model the morphology and associated grain sorting mechanisms and patterns of the gravel fraction of the sediments. The water discharge was maintained constant at $2.1 \mathrm{~L} \mathrm{~s}^{-1}$ throughout the experiment and the bed slope was set at $1.5 \%$. These values maintain $1 / 30$ Froude scaling of the Sunwapta River based on known highflow discharges, the bed material grain size distribution and the surveyed gradient of the river (Chew and Ashmore, 2001; Ashmore et al., 2011). The sediment system was closed to simulate long-term equilibrium conditions; a sediment pump transferred the output material to the upstream end of the flume, where it was returned continuously to the model river using a feed chute that allowed excess water to drain away. The $40 \mathrm{~h}$ period analyzed in this paper began at hour 140 of the experiment. Consequently, the flume bed was fully braided at the time of the initial DEM, some bed features were inherited from earlier in the experiment, and the braided pattern was maintained throughout the experiment.

\subsection{Bed topography}

Vertical stereo images of the dry bed were taken at $1 \mathrm{~h}$ intervals and DEMs were derived photogrammetrically (using Leica Photogrammetry Suite software v. 9.1) with a mean elevation error of $v=-0.02 \mathrm{~mm}$, standard deviation of $\sigma=0.78 \mathrm{~mm}$ and a cell size of $3 \mathrm{~mm}$ (Gardner and Ashmore, 2011). We consider an absolute error on height of $3 \sigma=2.3 \mathrm{~mm}$, which corresponds to a confidence interval of $99.7 \%$ for a normal distribution. The DEM extent in this analysis was $10 \mathrm{~m}$ long and $2.5 \mathrm{~m}$ wide to remove pho- togrammetric artifacts apparent near the edges and ends of the raw DEMs while covering the full braided river width. The final size on the DEM is $3334 \times 868$ cells. The flow increase and decrease lasted only a few minutes, and changes induced during that period are considered as negligible at the experiment scale.

\subsection{Grain size analysis}

The grain size analysis and mapping used the image texture method developed and tested by Carbonneau (2005) and Carbonneau et al. (2005) for field mapping of gravel-bed rivers but adapted for the sand texture in the physical model. The image texture calculation was made using the co-occurrence gray matrix level based on 64 gray level vertical bed images. The sampling window size of $7 \times 7$ pixels was chosen due to the median grain size $(1.3 \mathrm{~mm})$ and the camera resolution, and the best fit of the data was found using the entropy index. The entropy measures the quantity of common pattern on a picture. To calibrate the predictive relationship between an entropy value and the real grain size, two sets of measurements were used. Surface patches on the model river bed were sampled using adhesive and grain size was measured using physical sieving. The first set of 58 samples corresponded to patches with uniform grain size covering the range of sizes in the distribution (Gardner and Ashmore, 2011). This first set of 58 was extended with an additional 125 samples spread over an image area regardless of the surface composition and covering the full range of grain sizes and gradations. The 183 grain samples were split randomly into two sets: the first set was used to calibrate the linear relationship between sampled grain size and texture value (Fig. 1a) and the second set was used to validate the relationship and estimate the measurement error (Fig. 1b). With the validation set, we find that the mean value of the absolute error is $0.38 \mathrm{~mm}$ with a standard deviation of $0.61 \mathrm{~mm}$. The relative error on the absolute value ranges from 0 to $100 \%$ and half of the set had error less than $20 \%$.

We refer to the estimated grain size from the textural calibration as the "equivalent texture" because it is a texture value calibrated to only the median grain size (not the full distribution) for a patch and is not strictly a grain size value as conventionally defined in physical measurements of grain size.

A grain size map is associated with each DEM, and for every bed location the bed elevation and local bed texture is known (Fig. 2).

\subsection{Dimensionless bed depth}

During the $40 \mathrm{~h}$ of experiment time the bed elevation varied over a range of values at each location. From the minimum and maximum values at each point we define two specific surfaces: the minimum surface and the maximum surface denoted by the lowest and highest elevations at that point over 

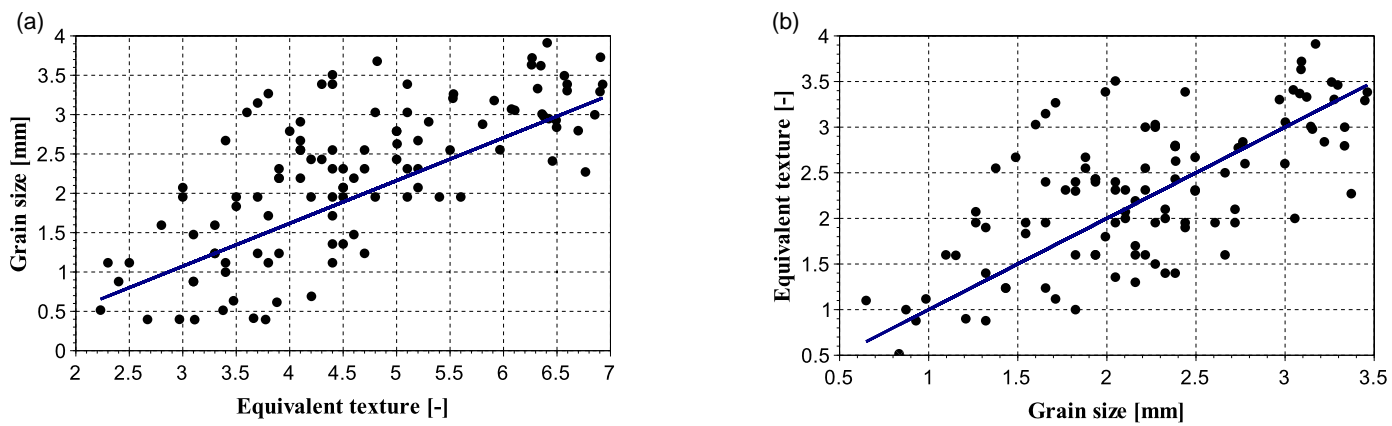

Figure 1. Calibration (a) and validation (b) data set for the predictive relationship between the surface grain size and the picture texture (entropy). A simple linear equation is used. The error estimation on the validation data set is $0.38 \mathrm{~mm}$ on the absolute mean value and $0.61 \mathrm{~mm}$ for standard deviation of the absolute value.

Orthoimage

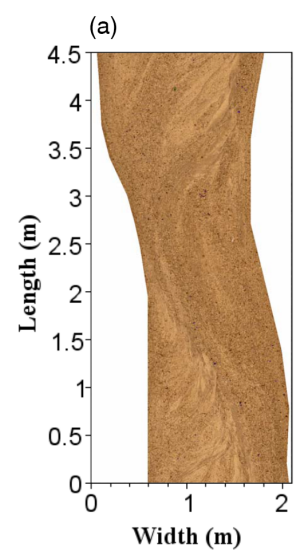

DEM

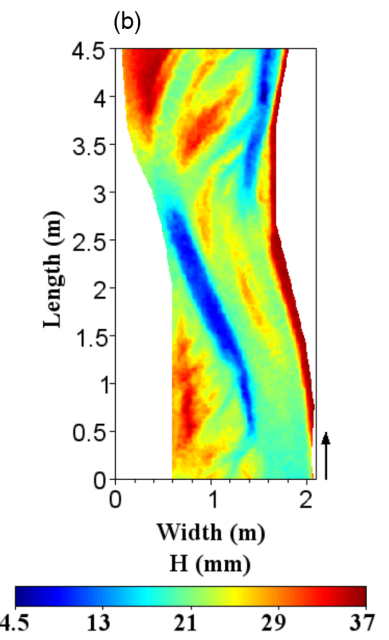

Equivalent texture
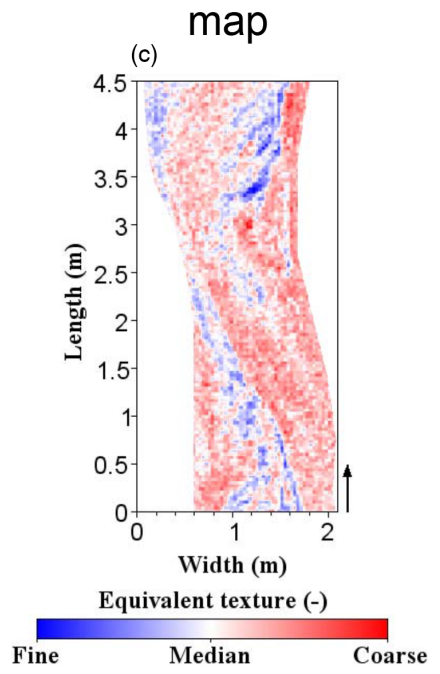

Figure 2. Summary of data acquisition. (a) Orthoimage: vertical pictures are taken at $1 \mathrm{~h}$ interval (note patterns of sorting of fine and coarse material). (b) DEM: the topography is derived photogrammetrically, the cell size is $3 \mathrm{~mm}$, and the flume slope is removed. (c) Equivalent texture map: the map is derived from the texture calculation of vertical pictures, and the median grain size error is less than $20 \%$.

the $40 \mathrm{~h}$ (Gardner and Ashmore, 2011). The difference between these two surfaces over the areal extent of the data is the morphological active layer (Fig. 3). The morphological active layer differs from deposit thickness because it is a virtual layer developed over time with virtual vertical extent larger than the deposits at any time. Moreover, the deposit thickness is time-related and changes with successive topography, whereas for a certain time interval the morphological active layer is constant. The morphological active layer is also different from the active layer involved in particle exchange during bedload transport because it extends over a depth related to overall scour and deposition of the river bed over the time-scale of reworking of the bed by braiding processes, rather than the near-surface particle exchange on a vertically stable bed during single bed-mobilizing events.

Although the river reworked the whole flume width during the experiment, some areas of the river bed were not active during the $40 \mathrm{~h}$. Those areas corresponded mainly to the tops of stable braid bars developed in earlier stages of the experiment. We define the areas that showed no measurable change by setting a uniform threshold of $4.6 \mathrm{~mm}$ according to the precision of the DEM. These "no-change" areas have been removed from DEMs and grain size maps so as to retain only the active part of the braided pattern in the analysis.

In a single set of DEM/equivalent texture maps, there is no clear link between the surface grain size and the bed elevation (Fig. 4). The longitudinal bed slope or the local bed topography might induce a complex relation even on a single set of bed elevation and local features (bar vs. channel). Yet, to study the grain sorting in the morphological active layer, the layer should be scaled relative to the absolute elevation to remove residual local topographic effects.

The raw bed topography was scaled by the local morphological active layer thickness (Eq. 1), where $\bar{h}(x, y)$ is 

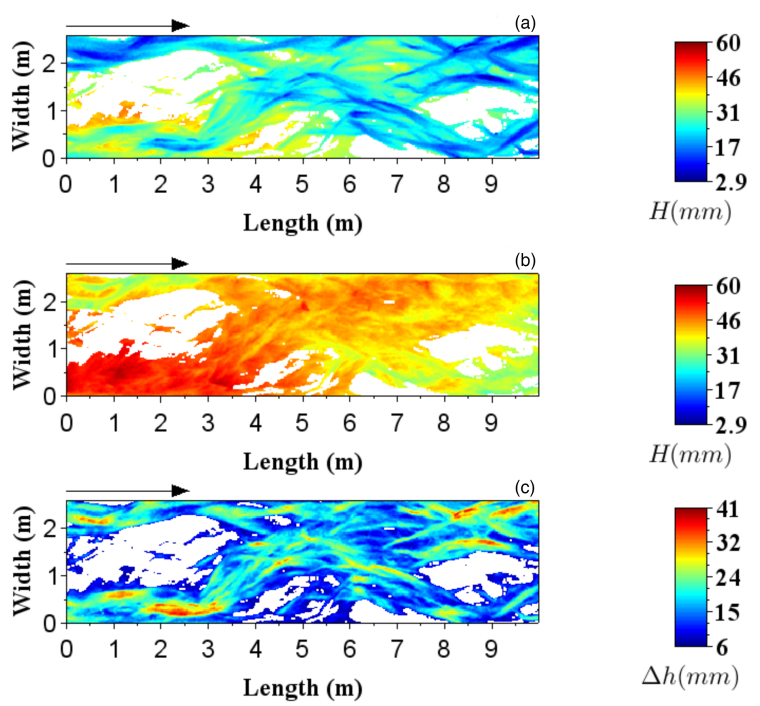

$H(\mathrm{~mm})$

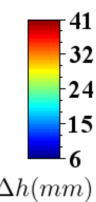

Figure 3. The minimum surface, the maximum surface and the morphological active layer. The minimum surface (a) is defined at the lowest elevation for each location throughout $40 \mathrm{~h}$. The maximum surface (b) is the highest elevation for each location throughout $40 \mathrm{~h}$. The morphological active layer (c) is the difference between the maximum surface (b) and the minimum surface (a). Whites parts are the no-change areas. The arrow indicates flow direction, and the flume slope is removed.

the dimensionless bed elevation, $H(x, y)$ the bed elevation in meters, $H_{\min }(x, y)$ the minimum elevation in meters, and $\Delta h(x, y)$ the morphological active layer thickness in meters. Dimensionless bed value ranges from 0 to 1 .

$\bar{h}(x, y)=\frac{H(x, y)-H_{\min }(x, y)}{\Delta h(x, y)}$

The normalization allows analysis of grain size changes in relation to the active layer thickness and local position within the vertical extent of the active layer.

\section{Analysis and results}

\subsection{Natural and modeled surface grain sorting}

During the period of analysis, a large proportion of the bed area was reworked by processes typical of braided rivers, i.e., channel avulsions, bar migration, bedload transport, confluence and bifurcation evolution, and active and non-active anabranches (e.g., Egozi and Ashmore, 2009).

Natural grain sorting is observed over the entire bed surface; fine and coarse sediments are organized in relation to local topography, flow bifurcation, bed roughness or flow constriction, which lead to a complex pattern of different surface grain size (e.g., Carson and Griffiths, 1987). Figure 5 shows a bar located at the downstream end of a confluence from a field site (Fig. 5a) and on the 1/30 downscaled flume model (Fig. 5b). In both pictures, small uniform fine grain

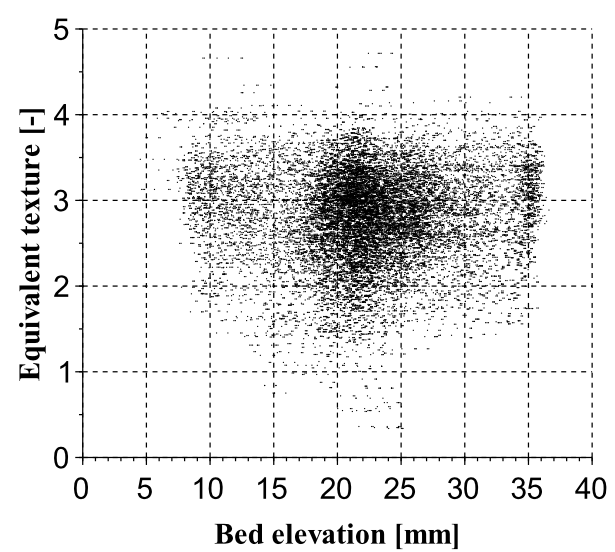

Figure 4. Example of equivalent texture as a function of bed elevation for a part of a single DEM: there is no clear trend between the equivalent texture and the local elevation for one set of measurements.

units are observed on the bar surface, with a longitudinal shape in bar length direction. The longitudinal shape of bars on the edge define a developed sorting pattern, as also described in Nelson et al. (2010). The braided channel in the flume also showed complex and diverse grain sorting patterns of the kind seen in full-scale braided rivers, including lateral sorting at confluences, coarse deposits on bar heads at bifurcations, fine-grained lateral bars on the downstream margins of braid bars, and lateral fining in bends and on bars (see also Moreton et al., 2002; Gardner and Ashmore, 2011).

\subsection{Bed layer construction}

From the normalized bed topography, 10 classes of dimensionless bed depth (Eq. 1 and Fig. 6a and b) are considered: ]0,0.1], ]0.1,0.2] ...]0.9, 1[. Values 0 and 1, which correspond respectively to the minimum surface and the maximum surface, are not included in the sublayer division to avoid imbalance in the amount of data within each layer the maximum and the minimum values always exist for each cell, whereas the intermediate values do not necessarily.

To create the texture map of layers, normalized bed topography of each DEM is distributed into the 10 classes of dimensionless bed depth (Figs. 7b and 6b). For each class, within each DEM, cells corresponding to the layer are associated with their equivalent texture value (Fig. 6c). From this process we get, for each class of normalized bed topography, 40 partial equivalent texture maps corresponding to each DEM (Fig. 6d). The resulting map is created by calculating the median value for each cell throughout the 40 partial maps (Figs. 6e and 8a-j). 
(a)

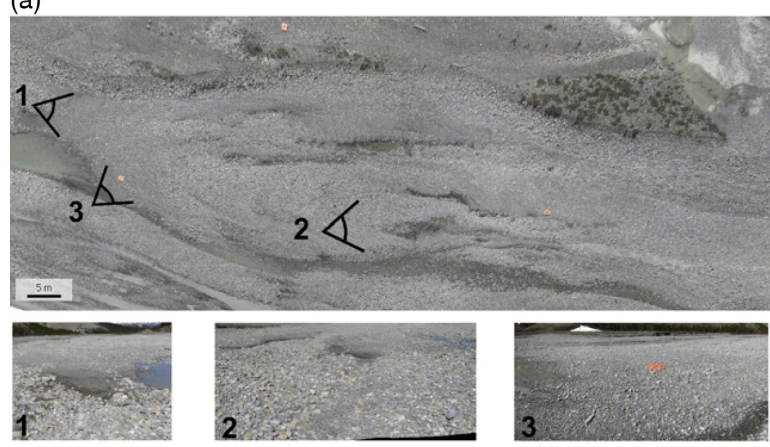

(b)

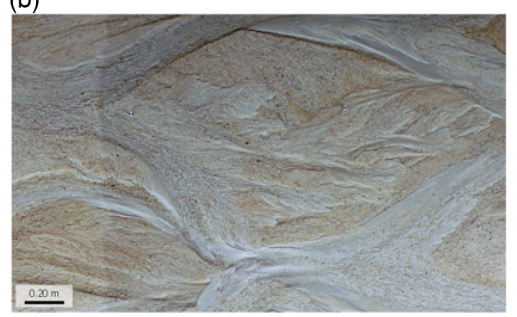

Figure 5. Grain sorting and natural pattern. (a) Vertical view of the Sunwapta River in the Canadian Rockies and (b) on the 1/30 model. Flow is from left to right in both bar pictures. Fine sediments are lighter gray than coarse sediments.

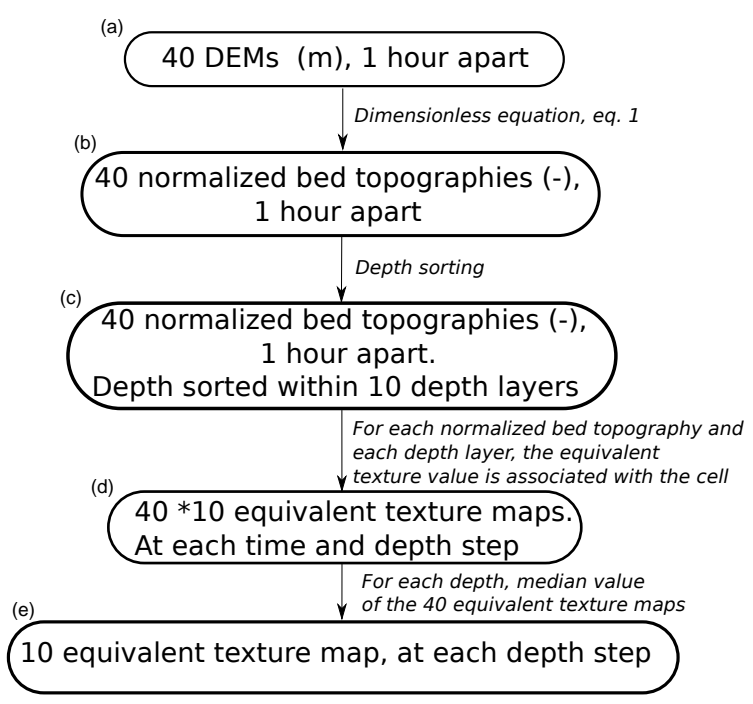

Figure 6. Construction of the texture maps: (a) the bed topography derived from the photogrammetry process, (b) the normalized bed topography using Eq. (1), (c) normalized bed topography sorted in 10 layers (the minimum and maximum surface are not included in the layers), (d) 400 equivalent texture maps, and (e) 10 median equivalent texture maps for each normalized bed depth.

\subsection{Equivalent texture distribution}

The equivalent textures of the different layers all cover the same range of values. Within the morphological active layer each equivalent texture can be found in every layer, every layer has the full range of equivalent texture values, and the proportion of equivalent textures is almost identical for all layers (Fig. 9).

The shift of the equivalent texture distribution for the first two layers just above the minimum surface indicates that the average equivalent texture is slightly coarser for layers near the minimum surface (Fig. 9). The total number of data points is small compared to other layers due to the slight local aggradation in part of the flume during the experiment.

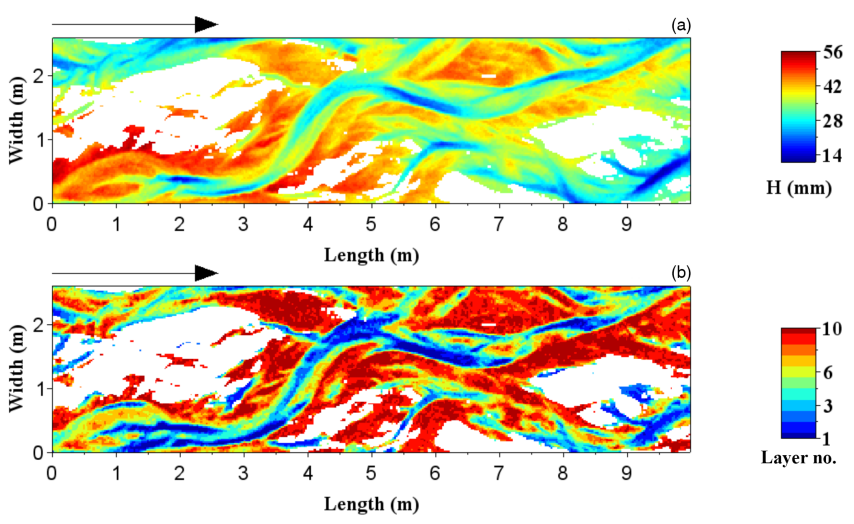

Figure 7. The bed elevation is normalized by the morphological active layer thickness. On initial topography (a), local topographic gradients affect local elevation of features. On normalized topography (b), equivalent features all have elevation shown by the same range of color over the model extent; for example, channels are blue and high bar tops dark red. The flume slope is removed.

Nevertheless, among those points, this small coarse shift reflects the increased presence of coarse patches in the lower parts of the morphological active layer.

In this study we assessed the grain size variation vertically within the morphological active layer of a physical model of a gravel-bed braided river. To avoid slope and topography bias, the bed topography was normalized and the results demonstrate that, aggregated at the scale of the major morphological units of a braided channel, there is no strong vertical trend in the median size. Every equivalent texture occurs in each layer with approximately equal frequency. However, focusing on the coarse end of the equivalent texture distribution, there is a slight tendency for more coarse patches in the lower part of the morphological active layer. The presence of these coarse patches may relate to particular morphological features inherited from morpho-textural patterns on the river bed. For example, Fig. 10 shows the localization of the coarse patches (regardless of bed depth) and anabranch 

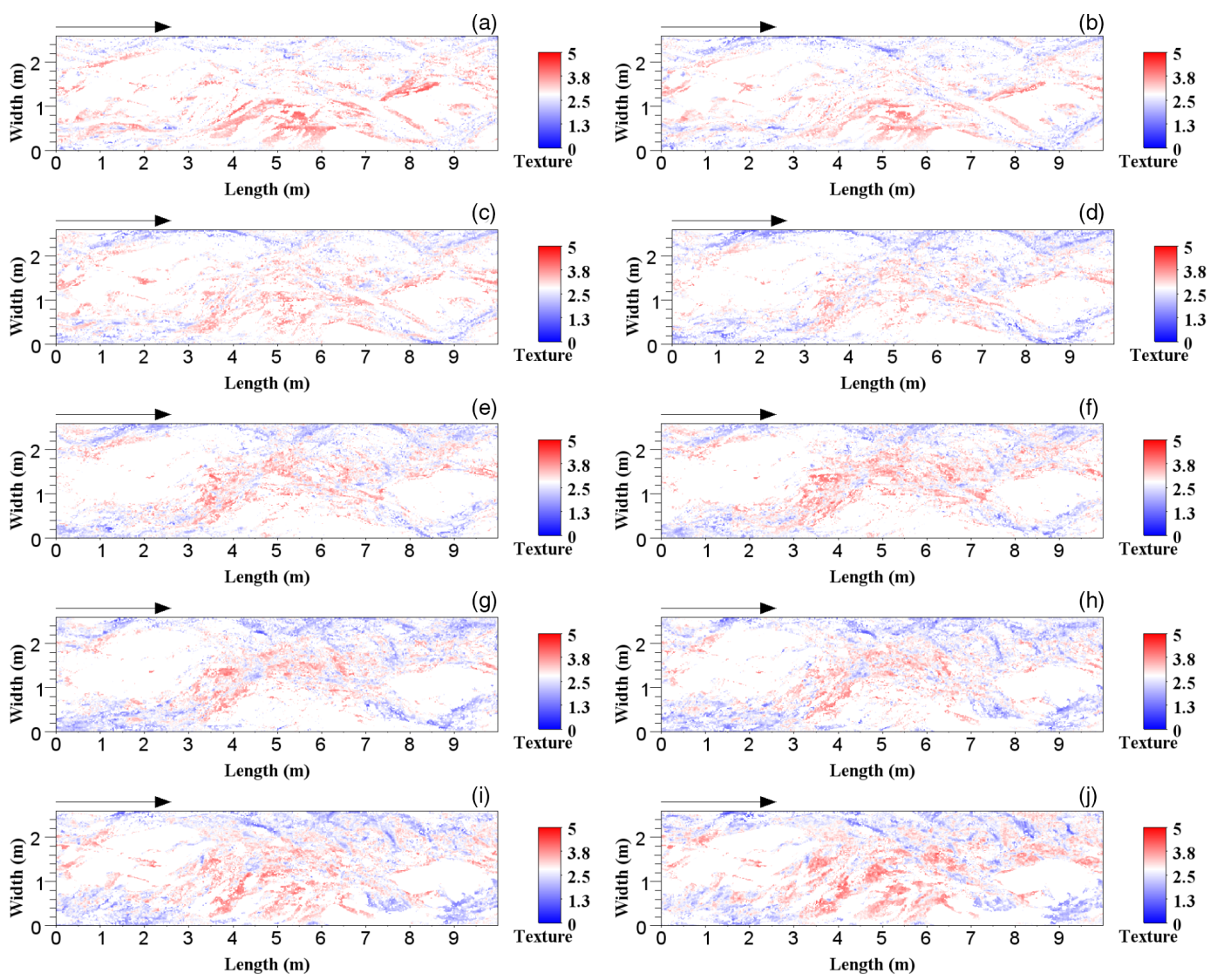

Figure 8. Equivalent texture maps: layer 1 (a), layer 2 (b), layer 3 (c), layer 4 (d), layer 5 (e), layer 6 (f), layer 7 (g), layer 8 (h), layer 9 (i), and layer $10(\mathbf{j})$. The white part of the color scale is centered around the median value (2.7) of the distribution combined.

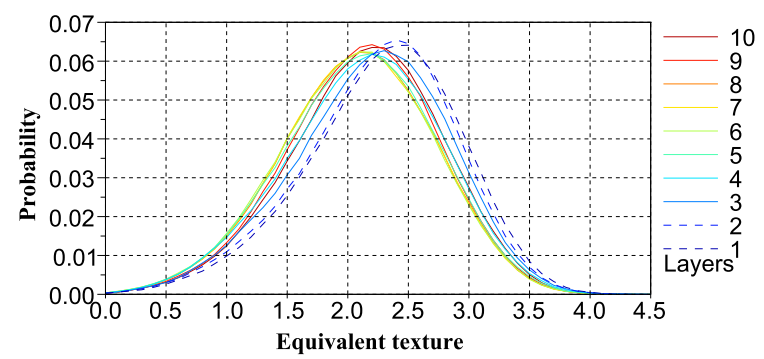

Figure 9. Equivalent texture histogram. The dashed lines represent the lower layers: layers 1 and 2 . The shift of the equivalent distribution of those two layers indicates that the median equivalent texture is slightly higher close to the minimum surface.

confluences. Confluences were identified manually (Gardner, 2009), and the map (Fig. 10) shows time-integrated confluence positions. The majority of coarse patches are located on the confluence area or in the downstream channel. These coarse patches may correspond to "fixed" grain patches because of their location close to confluences (Nelson et al., 2009, 2010). Further analysis of these and other features is needed to understand the relationship between texture and

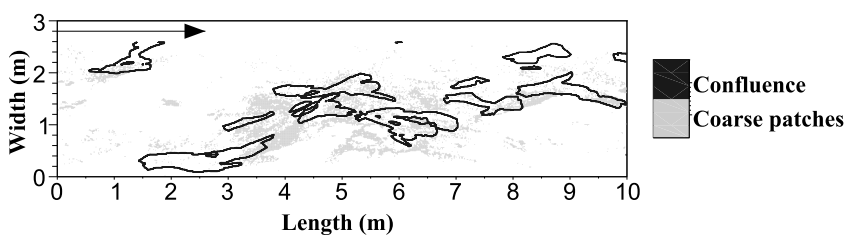

Figure 10. Confluence and coarse patches map. Black lines are the boundaries of confluence areas over $40 \mathrm{~h}$. Gray dots are coarse patches.

channel morphology at the reach scale to explain details of size sorting within the morphological active layer.

\section{Discussion}

Overall the results indicate that, while local sorting patterns are complex, the morphological active layer can be considered, on aggregate at reach scale, to be homogeneous with respect to median grain size between sedimentary layers of the bed. In other words, there is nearly equal probability of encountering any texture value at any relative elevation within the morphological active layer. This is consistent with some 
observations suggesting very little general vertical sorting trends within gravelly braided alluvium (Lunt and Bridge, 2004; Guerit et al., 2014). In morphological approaches to computing bedload transport in braided rivers (Ashmore and Church, 1998) it is implicit that transport involves the entire morphological active layer. From our results a good firstorder approximation of grain sizes available for transport is that all grain sizes are equally available at all elevations in the morphological active layer over relevant morphodynamic timescales.

Therefore, available sediments at any location and time match the bulk size distribution of the morphological active layer. This also provides both an initial basis for numerical modeling of bedload transport in braided rivers with mixed sediment sizes (e.g., Sun et al., 2015) and a means for mutual testing of grain size sorting in physical and numerical models, for which limited and strategic field sampling could provide validation.

\section{Conclusions}

A physical model of a gravel braided river provided data on the range of elevation values from a sequence of photogrammetric DEMs covering $40 \mathrm{~h}$ of model time. From these data the vertical extent of the morphological active layer of the river can be defined at any location. Textural analysis of the photogrammetric images yields equivalent texture (median grain size) at any location on each DEM and therefore a complete three-dimensional picture of grain size variation in the morphological active layer during active development of the braided river. Analysis of the bed elevation layers normalized by active layer depth shows that the morphological active layer is approximately homogeneously mixed except for some slightly higher proportions of coarse texture in the lowermost layers. Further analysis of the distributions is needed to understand how this mixing develops in relation to bed scour and deposition in braided rivers. The result provides an initial approximation of grain size variation for numerical modeling of morphodynamics of braided rivers with mixed size sediment incorporating local size sorting and tracking the grain sizes at any location within the morphological active layer.

Acknowledgements. This research was supported by a Natural Sciences and Engineering Research Council of Canada award to P. Ashmore. The Canada Foundation for Innovation and Newalta Resources Inc. funded the flume construction. We thank Jim Chandler and Rene Wackrow for their support in applying the photogrammetric methods. Several people assisted with the experiments, especially Roey Egozi and Beth Hundey.

Edited by: D. Parsons

\section{References}

Ashmore, P. and Church, M.: Sediment transport and river morphology: a paradigm for study, Water Resources Publications LLC, Highlands Ranch, Colorado, 115-148, 1998.

Ashmore, P., Bertoldi, W., and Gardner, T. J.: Active width of gravel-bed braided rivers, Earth Surface Processes and Landforms, 36, 1510-1521, 2011.

Ashworth, P., Ferguson, R., and Powell, D.: Bedload transport and sorting in braided channels, 497-518, 1992.

Bluck, B.: Structure of coarse grained braided stream alluvium, Transactions of the Royal Society of Edinburgh, 70, 181-221, 1979.

Carbonneau, P. E.: The threshold effect of image resolution on image-based automated grain size mapping in fluvial environments, Earth Surface Processes and Landforms, 30, 1687-1693, 2005.

Carbonneau, P. E., Bergeron, N., and Lane, S. N.: Automated grain size measurements from airborne remote sensing for long profile measurements of fluvial grain sizes, Water Resour. Res., 41, doi:10.1029/2005WR003994, w11426, 2005.

Carson, M. A. and Griffiths, G. A.: Bedload Transport in Gravel Channels, New Zealand Hydrological Society, J. Hydrol., 26, 1151, 1987.

Chew, L. and Ashmore, P. E.: Channel adjustment and a test of rational regime theory in a proglacial braided stream, Geomorphology, 37, 43-63, 2001.

Egozi, R. and Ashmore, P.: Experimental analysis of braided channel pattern response to increased discharge, J. Geophys. Res.Earth, 114, doi:10.1029/2008JF001099, f02012, 2009.

Gardner, J.: Morpho-dynamics and sedimentology of confluences in gravelly braided rivers, $\mathrm{PhD}$ thesis, University of Western Ontario, London, Canada, 235 pp., 2009.

Gardner, J. and Ashmore, P.: Geometry and grain-size characteristics of the basal surface of a braided river deposit, Geology, 39, 247-250, 2011.

Guerit, L., Barrier, L., Narteau, C., Métivier, F., Liu, Y., Lajeunesse, E., Gayer, E., Meunier, P., Malverti, L., and Ye, B.: The Grainsize Patchiness of Braided Gravel-Bed Streams - example of the Urumqi River (northeast Tian Shan, China), Adv. Geosci., 37, 27-39, doi:10.5194/adgeo-37-27-2014, 2014.

Haschenburger, J. K.: Vertical mixing of gravel over a long flood series, Earth Surf. Proc. Land., 36, 1044-1058, 2011.

Heinz, J., Kleineidam, S., Teutsch, G., and Aigner, T.: Heterogeneity patterns of Quaternary glaciofluvial gravel bodies (SWGermany): application to hydrogeology, Sediment. Geol., 158, 1-23, 2003.

Leduc, P.: Etude expérimentale de la dynamique sédimentaire des rivières en tresses, $\mathrm{PhD}$ thesis, Université de Grenoble,Grenoble, France, 236 pp., 2013.

Lunt, I. and Bridge, J.: Evolution and deposits of a gravelly braid bar, Sagavanirktok River, Alaska, Sedimentology, 51, 415-432, 2004.

Marren, P. M.: Magnitude and frequency in proglacial rivers: a geomorphological and sedimentological perspective, Earth-Sci. Rev., 70, 203-251, 2005.

Moreton, D. J., Ashworth, P., and Best, J. L.: The physical scale modelling of braided alluvial architecture and estimation of subsurface permeability, Basin Res., 14, 265-285, 2002. 
Nelson, P. A., Venditti, J. G., Dietrich, W. E., Kirchner, J. W., Ikeda, H., Iseya, F., and Sklar, L. S.: Response of bed surface patchiness to reductions in sediment supply, J. Geophys. Res.-Earth, 114, F02005, doi:10.1029/2008JF001144, 2009.

Nelson, P. A., Dietrich, W. E., and Venditti, J. G.: Bed topography and the development of forced bed surface patches, J. Geophys. Res.-Earth, 115, F04024, doi:10.1029/2010JF001747, 2010.

Sambrook Smith, G.: Small-scale cyclicity in alpine proglacial fluvial sedimentation, Sediment. Geol., 132, 217-231, 2000.

Storz-Peretz, Y. and Laronne, J. B.: Automatic grain sizing of vertical exposures of gravelly deposits, Sediment. Geol., 294, 13-26, 2013a.

Storz-Peretz, Y. and Laronne, J. B.: Morphotextural characterization of dryland braided channels, Geol. Soc. Am. Bull., 125, 1599-1617, 2013b.

Sun, J., Lin, B., and Yang, H.: Development and application of a braided river model with non-uniform sediment transport, Adv. Water Resour., 81, 62-74, doi:10.1016/j.advwatres.2014.12.012, 2015.
Van De Lageweg, W., Van Dijk, W., and Kleinhans, M.: Morphological and stratigraphical signature of floods in a braided gravelbed river revealed from flume experiments, J. Sediment. Res., 83, 1032-1045, 2013.

Viparelli, E., Haydel, R., Salvaro, M., Wilcock, P. R., and Parker, G.: River morphodynamics with creation/consumption of grain size stratigraphy 1: laboratory experiments, J. Hydraul. Res., 48, 715-726, 2010.

Wheaton, J., Brasington, J., Darby, S., Kasprak, A., Sear, D., and Vericat, D.: Morphodynamic signatures of braiding mechanisms as expressed through change in sediment storage in a gravel-bed river, J. Geophys. Res.-Earth, 118, 759-779, 2013. 